\title{
Sub-Pontic Osseous Hyperplasia: A Case Report
}

\author{
Khaled Waleed Sadig ${ }^{1}$ and Mohammed Ahmed Al Attas ${ }^{2 *}$ \\ ${ }^{1}$ Specialist in Prosthodontic, Dental college, Riyadh Elm University, Riyadh, Saudi \\ Arabia \\ ${ }^{2}$ Consultant in Prosthodontic, Dental Implant and Maxillofacial Prosthodontics, \\ Riyadh Dental Hospital, King Saud Medical City, Riyadh, Saudi Arabia \\ *Corresponding Author: Mohammed Ahmed Al Attas, Consultant in Prosthodontic, \\ Dental Implant and Maxillofacial Prosthodontics, Riyadh Dental Hospital, King Saud \\ Medical City, Riyadh, Saudi Arabia.
}

Received: February 12, 2021

Published: April 08, 2021

(C) All rights are reserved by Khaled Waleed Sadig and Mohammed Ahmed Al Attas.

\begin{abstract}
Background and Objective: Soft tissue impingement, faulty oral hygiene measures, and faulty long span bridges especially mandibular implant supported fixed partial dentures can create trauma under the pontic area, functional occlusal stresses and hyperactivity of the muscles forming a bony hyperplasia beneath the pontic area. The objectives of this case report were to present the Sub-pontic osseous hyperplasia clinical case history, explain different treatment methods, and review the literature regarding sub-pontic osseous hyperplasia condition.

Results: Based on radiographic findings, enlargement and extension in the sub-pontic region that is mostly perceived as more radiopaque than the adjacent alveolar cortical bone. Based on Histo- pathologic findings, the lesion bony growth expressed similar histology to that of ordinary compact dense cortical bone. The bony growth dimension is reliant on the pontic width, the height of the lower boundary of the pontic and on the growth phase at which the hyperplasia of the bone is detected.

Conclusion: Sub-pontic osseous hyperplasia is a non-common disease that occur in the pontic area due to pressure and continuous irritation to the underlying tissues, yet, dental clinicians should always consider other possible factors as occlusal stresses, prosthetic material biocompatibility. It does not typically necessitate treatment or taking biopsy but, removing the cause of irritation.
\end{abstract}

Keywords: Sub-Pontic Osseous Hyperplasia; Bone Growth; Pontic Bone Exostoses; Pontic Hyperplasia

\section{Introduction}

Sub-pontic osseous hyperplasia $(\mathrm{SOH})$ is a slowly developing ectopic, non-neoplastic growth of bone that exclusively affects the lower posterior ridges that is edentulous beneath the pontic region of the fixed dental prosthesis. A sub-pontic osseous hyperplasia can cause serious periodontal and restorative problems, on the other hand, it is commonly treated by surgical removal [1]. This report presents all about the causes and treatment of sub-pontic osseous hyperplasia, along with a SOH case report.
A few numbers of situations and malformations appear on the edentulous ridges. As a fact, the relevant subgroup classification arrangement presented six clinical defects or conditions starting with the vertical and/or horizontal ridge insufficiency, absence of gingiva or keratinized soft tissue, soft tissue expansion, abnormal frenum position, reduced vestibular depth, and lastly color change [1]. From these conditions sub-categories, only ridge insufficiency can be reflecting the edentulous ridges abnormalities. Sub-pontic osseous hyperplasia is a deformity explicit to edentulous ridges conditions. $\mathrm{SOH}$ is a condition that was first presented by Calman., 
et al. in the early of 1970 as a non-malignant ectopic growing bone below the pontic area of the fixed dental prosthesis [2].

SOH is comparatively infrequent, frequently asymptomatic, and can happen or take place from some months to several years after the fixed dental prosthesis cementation [3]. The deformity characteristically represents unilateral bone growth even in the existence of bilateral fixed dental prosthesis, and has a preference for the mandibular ridge, predominantly the first molar Pontic area [4-6]. Usually, both the histological and radiographic structures of $\mathrm{SOH}$ are matching with normal picture represented as compact and lamellar bone which is the same to other bony exostoses [2,5-7]. SOH lesion size and shape is governed by its growth phase, the measurement of the edentulous area, and the location and outline of the pontic area inferior border [6]. Numerous etiologic influences have been proposed, but the precise etiologic factor of $\mathrm{SOH}$ continues to be unknown [3].

In some cases, sub-pontic osseous hyperplasia maybe non-observed by many patients, yet the common thing between these patients is that they all strive and face difficulty in cleaning under the pontic area $[3,5,6]$. Limited number of studies that described clinical cases that include patients who mentioned pressure, sensitivity and maybe pain under the pontic area [6,8-11]. The increasing size of the SOH may encroach on the fixed dental prosthesis pontic(s), causing the FDP to be come loose or even dislodged [3,5,6]. Gradual increase in the difficulty to access to the abutment teeth for proper oral hygiene measures could result in the development of caries [5]. The improper oral hygiene associated with the sub-pontic osseous hyperplasia will cause localized inflammation of the gingival and loss in the periodontal attachment around the abutment teeth $[5,7,8]$. Restorative complications and also periodontal accompanying $\mathrm{SOH}$ are the main reasons for the treatment of this condition, which normally is surgical excision $[5,6]$. The aim of this case report study is to present a $\mathrm{SOH}$ clinical case history, explain $\mathrm{SOH}$ different treatment methods, and review the literature regarding sub-pontic osseous hyperplasia condition.

\section{Case Discussion}

A 62-year-old female patient having blood hypertension presented to our clinic at Riyadh Elm University dental hospital Olaya campus in year 2019 with a chief complaint of pain related to lower left FDP. The prosthetic restoration was positioned 6 years ago. patient chief complaint is pain and odor from fixed three unit fixed dental prosthesis Intraoral examination discovered a hard bony swelling that showed no pain upon palpation, this swelling was below the pontic area of a three unit fixed dental prosthesis that replaced a missing lower left first molar (Figure 1).

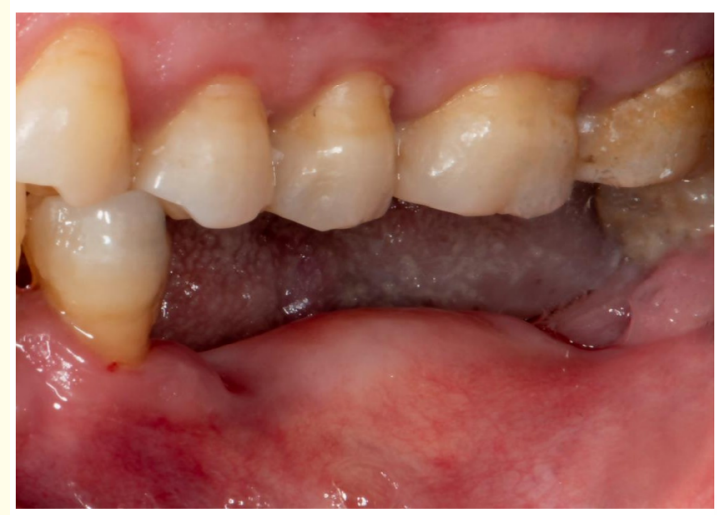

Figure 1: Clinical photography of nodular bony graft after FDP removal and extraction of both of lower left second premolar and second molar.

Radiographic examination showed the development of a bony growth underneath the pontic area, which exhibited more radiopaque than the adjacent bone and recurrent caries was recognized at the lower left second premolar (Figure 2). After removal of the fixed dental prosthesis, Diagnosis of the sub-pontic osseous hyperplasia was confirmed based on radiographic and clinical findings. The lesion was painless, extraction was done to for the lower left second premolar and second molar (Figure 3). Dental implant was planned to restore the edentulous area.

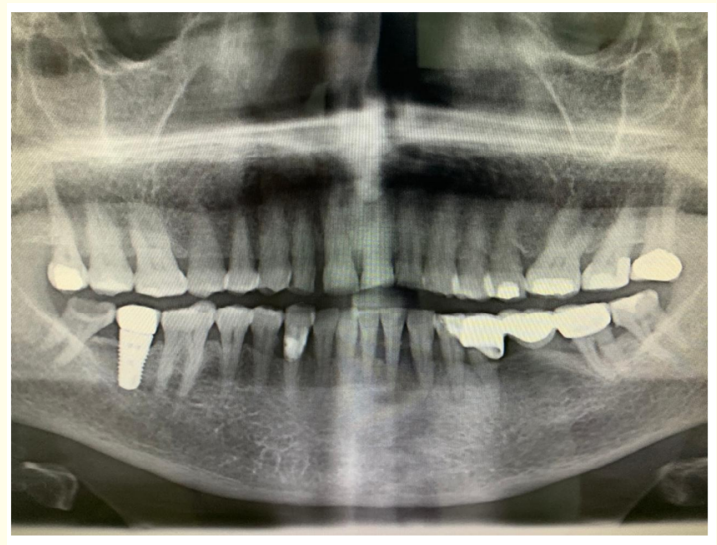

Figure 2: Panoramic radiograph of FDP and nodular bony growth. 


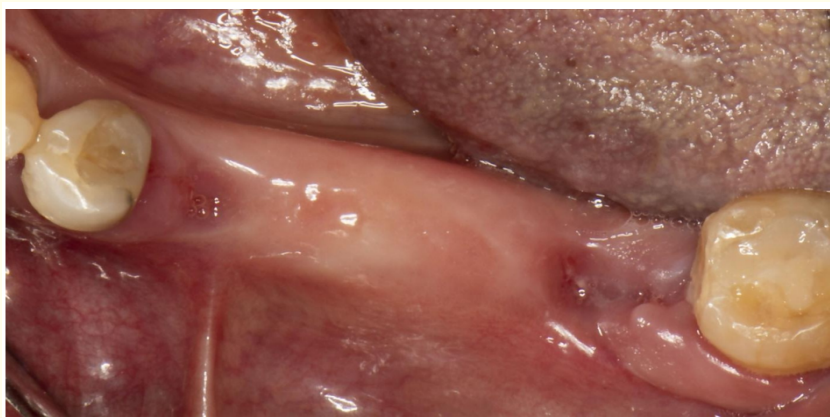

Figure 3: Occlusal view of nodular bony graft after FDP removal and extraction of both of lower left second premolar and second molar.

\section{Discussion and Literature Review}

The current article documented a bony radiopaque nodular growth that happened under a pontic of a three-unit bridge. The lesion was diagnosed clinically as sub-pontic osseous hyperplasia in the mandibular first molar region. The managing of this benign slowly growing bony lesion is by surgical removal, with the aid of a rotary instruments or piezoelectric surgery. The bone removed from this bony tissue growth might be a potential autogenous bone graft source if needed. SOH has been described in the literature review as bone osteoma, hyperostosis, sub-pontic osseous propagation, sub-pontic bony deposition, reactive sub-pontic exostosis, irritate sub-pontic hyperostosis, external hyperostosis alveolaris, and sub-pontic tissue enlargement [2-4,6-18].

The average patient age identified with $\mathrm{SOH}$ was in an age of 55 years. SOH displays equally in both females and males, usually as a unilateral condition in $80 \%$ of the identified cases. $\mathrm{SOH}$ was significantly expressed in the mandibular edentulous region more marked in posterior area that contain a fixed prosthesis. Most of the cases developed sub-pontic osseous hyperplasia after 7 years of cementing the fixed partial denture [3]. Previous case reports stated that the radiographic findings of $\mathrm{SOH}$ is more radiopaque than the edentulous ridge below the pontic area, with a more affinity to become more radiopaque with time. At the same time, other case reports found combined radiopaque/radiolucent bony growth rather than fully radiopaque, at last minor cases found thin radiolucent line demarcation between the lesion and edentulous ridge $[3,4,6$ $8,18]$.
The typical approach to SOH management has been to excise the bony growth $[3,5,7-9,16]$. Return and reappearance of this lesion after removal is rare $[3,5,16]$. Removal of the FPD and replacing the missing teeth with dental implants is a successful part of the SOH managing $[3,5,8,9,16]$. The reason or cause of the osseous hyperplasia has not been conclusively recognized. The most frequently advocated causative factors have been occlusal load, continuing localized tissue irritation, or both theory combination $[2-7,11,12,19,20]$. The likely part of genetics has also been proposed $[3,6,11,17,21]$.

Some of the suggested etiologic causes of SOH were soft tissue impingement, faulty oral hygiene measures can create trauma under the pontic area, formation of electric currents, functional occlusal stresses and hyperactivity of the muscles $[6,8,11,15,17,22]$. The mandible flexes and relax every time it opens and close resulting in more functional stresses and tension in the fixed partial denture area shape, therefore activate more bone growth under the pontic [23-25].

Stress concentration was found by Ralph and Caputo on the cortical bone when vertical pressure is applied inside the mandible [26]. The difference in the cortical plate of bone content and thickness, and the difference pattern of mouth movement of the mandible versus the maxilla are all factors that govern the fact that $\mathrm{SOH}$ are usually expressed in the mandible. Almost most of the SOH cases take place under neath a bar-like pontic it is probable that this pontic design allows maximum bend that create the highest stress over the edentulous ridge this is mainly due to the thinning of the connector area compared to the pontic thickness.

In most reported cases, $\mathrm{SOH}$ has been detected under long span bridges especially mandibular implant supported fixed partial dentures $[27,28]$. Especially the molar mandibular area is predominantly subject to reactive bone creation in reaction to occlusal functional load irrespective from the origin of stresses whether from tooth-supported fixed partial denture or implant supported prostheses.

Diagnosis of SOH is by taking into considerations the patient's history along with the clinical and radiographic outcomes, and it was specified that the occurrence of a FPD boosts the diagnostic confirmation of sub-pontic osseous hyperplasia. On the other hand, keep in mind that other conditions and pathosis might be found under pontic area and not every under pontic condition is considered $\mathrm{SOH}$. Sub-pontic osseous hyperplasia in rare cases can develop into 
osteitis osteomyelitis and maybe Gardner's syndrome. Any suspected condition or bony growth has to be biopsied and conclusive diagnosis is usually reached by the aid of histo-pathologic consideration [23].

$\mathrm{SOH}$ can be find in both genders with a broad range of age. The mean age for patients with $\mathrm{SOH}$ is $\mathbf{5 5}$ years, with an equal male to female ratio. The pre disposition of the disease is not conclusively in the mandible and can occur in the maxilla yet, most of the cases documented in literature exists in the mandible [21].

Diminution of the condition after the removal of the fixed partial denture increase the evidence fact that functional loads act as an etiologic cause. Nevertheless, diminution does not eliminate the existence of other potential etiologic influences and the precise cause of this bony enlargement is still unknown [26].

In several clinical cases, the patients didn't observe or notice and have any complain from the condition. Other patient's complaint from loose fixed partial dentures, fractured FDP connector, pain from the abutment teeth under the pontic pain that usually led to the diagnosis of $\mathrm{SOH}$. Incapability to clean and floss under the pontic was the utmost common SOH complaint, but who complained or noticed a bony growth under the pontic area [20].

The soft tissue under the pontic area is clinically is in near contact with the surface of the pontic, and in most cases, the space under pontic is entirely blocked. The condition presents as a solitary bony growth nodular in shape under the pontic. In literature, other bony growth shapes have been described to be bi-lobed in shape. The bony growth on palpation was stated as strong and hard as bone and this property was also noticed in our case report [21].

Most SOH cases occur under bar-like or hygienic pontics; it is possible that such pontic designs allow for higher bending stress distribution on the edentulous ridge, due to connectors that are thinner in comparison to other pontics like Ovate and modified hygienic

Regarding radiographic findings, enlargement and extension that decreases the sub-pontic region is mostly perceived as more radiopaque than the adjacent alveolar cortical bone. In some $\mathrm{SOH}$ cases, the shift between the lesion bony growth and the neighboring cortical bone is smooth and in other cases there is a clear distinct intersection. In other patients a tinny radiolucent link separates the enlarged bony growth from the beneath bone. In some cases, sclerotic response was detected in the bone surrounding the lesion in the edentulous ridgearea [20]. The radiographic findings of sub-pontic osseous hyperplasia are presented in (Table 1).

\begin{tabular}{|c|}
\hline Dense more radiopaque than edentulous ridge \\
\hline Compact bone with no trabecular form, sclerotic pattern \\
\hline Trabeculated bone \\
\hline Smooth outline \\
\hline In some cases, motley Radiopacity \\
\hline Dome shaped lesion \\
\hline Lobulated, and nodular bony growth \\
\hline
\end{tabular}

Table 1: Sub-pontic osseous hyperplasia radiographic findings.

The bony growth dimension is reliant on the pontic width, the height of the lower boundary of the pontic and on the growth phase at which the hyperplasia of the bone is detected. In some patients the size of the lesion didn't change after being noticed, and in other cases, the bony growth showed an increased size at every appointment [6].

Based on histo-pathologic SOH findings, the lesion bony growth expressed similar histology to that of ordinary compact dense cortical bone. Our case was not biopsied; on the other hand, the enlarged bony growth was clinically and radiographically characteristic as that of $\mathrm{SOH}$ and displayed decrease in size after fabrication of a new fixed partial denture, therefore confirming the primary SOH diagnosis. Sub-pontic osseous hyperplasia is essential to be surgically excised when it doesn't permit prosthesis construction, or affect the aesthetic and phonetic capabilities, or if it is causing chronic inflammation, affects proper oral hygiene measures, and finally cause chronic periodontal diseases [20].

\section{Treatment}

Of many viable options the Treatment decision in this case comprises surgical removal and bone re-contouring (Figure 4) and are accompanied by placing three dental implants at the edentoulous site and at the $\mathrm{SOH}$ site (Figure 5). It was observed that the hyper plastic bone was soft and spongy $[2,6,13,16]$. A screw retained fixed dental prosthesis superstructure was fabricated on implants (Figure 6). Follow-up is endorsed due to potential recurrence [16]. No recurrence was observed 6 month later (Figure 7). 


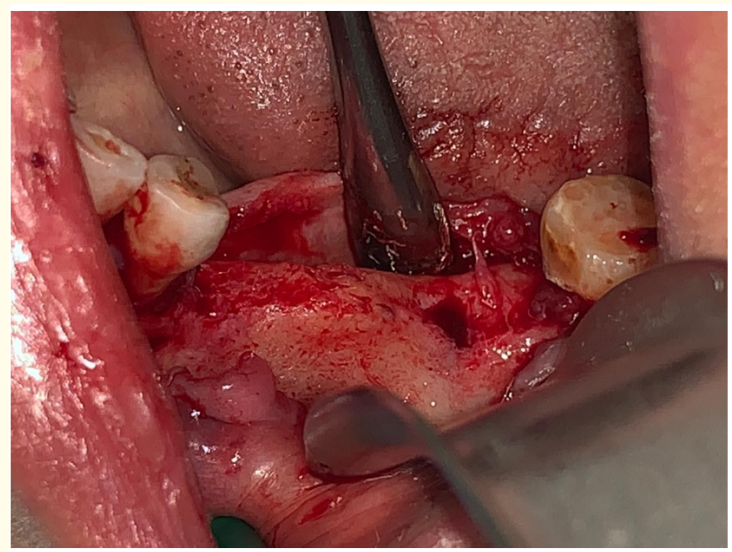

Figure 4: Full flap raised for implant placement.

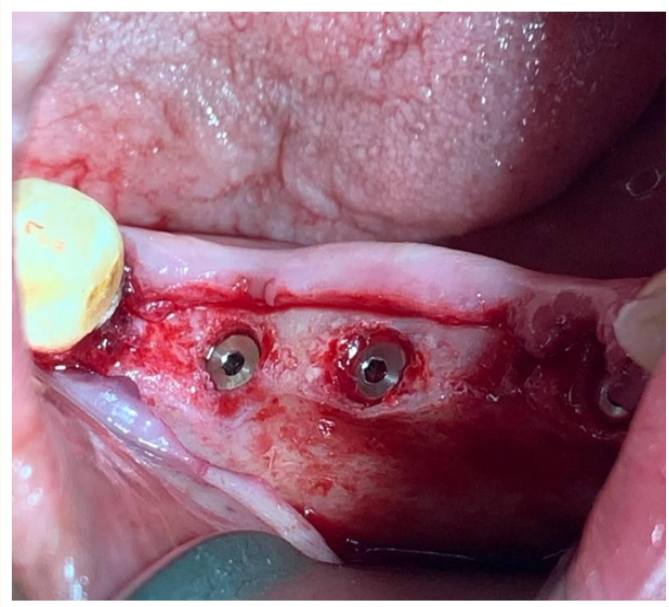

Figure 5: Three dental implants placed.

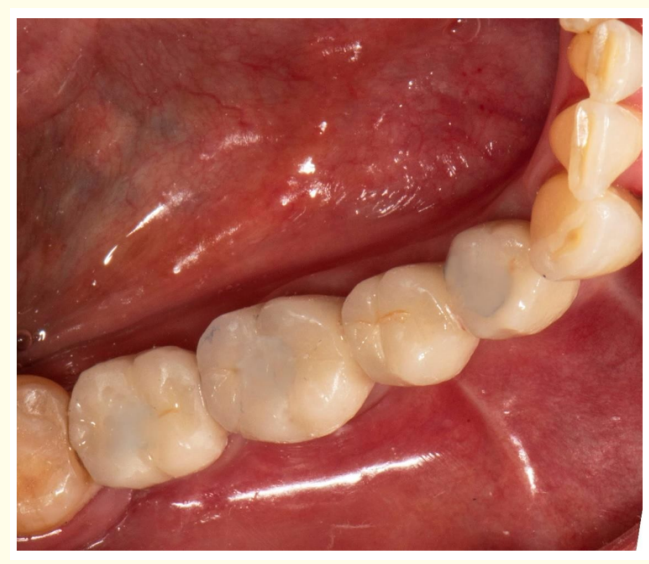

Figure 6: Screw retained FDP after insertion.

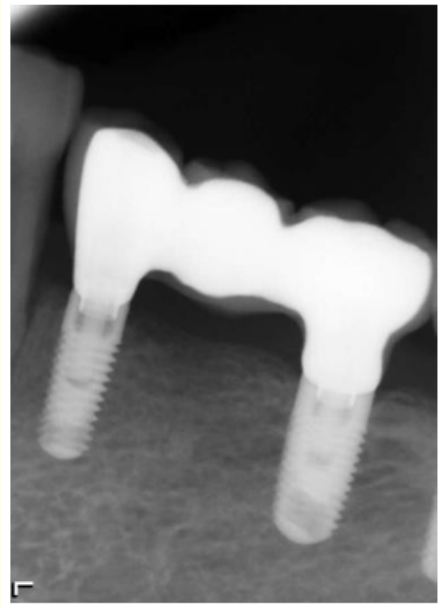

Figure 7: Periapical radiograph follow up after FDP placement.

\section{Conclusion}

$\mathrm{SOH}$ is a non-common disease that occur in the pontic area due to pressure and continuous irritation to the underlying tissues, yet, dental clinicians should always consider other possible factors as occlusal stresses, prosthetic material biocompatibility. SOH does not typically necessitate treatment or taking biopsy.

\section{Bibliography}

1. Abramovitch K. "Roentgen ray anomalies [Pontic hyperostosis]". Journal Gt Houst Dent Soc 64 (1993): 4.

2. Appleby DC. "Investigating incidental remission of subpontic hyperostosis". The Journal of the American Dental Association 122 (1991): 61-62.

3. Armitage GC. "Development of a classification system for periodontal diseases and conditions". Annals of Periodontology 4 (1999): 1-6.

4. Beaumont RH. "Subpontic osseous proliferation over a period of 22 years: a case report". Northwest Dent 76 (1997): 34-35.

5. Bouquot JE and Gundlach KK. "Oral exophytic lesions in 23,616 white Americans over 35 years of age". Oral Surgery, Oral Medicine, Oral Pathology, and Oral Radiology 62 (1986): 284-291.

6. Burkes EJ., et al. "Subpontic osseous proliferation". Journal of Prosthetic Dentistry 53 (1985): 780-785. 
7. Cailleteau JG. "Subpontic hyperostosis". Journal of Endodontics 22 (1996): 147-149.

8. Calman HI., et al. "Shades of white. Interpretation of radiopacities". Dent Radiogr Photogr 44 (1971): 3-10.

9. Daniels WC. "Subpontic osseous hyperplasia: a five-patient report”. Journal of Prosthodontics 6 (1997): 137-143.

10. Frazier KB., et al. "A case report of subpontic osseous hyperplasia in the maxillary arch". Oral Surgery, Oral Medicine, Oral Pathology, and Oral Radiology 89 (2000): 73-76.

11. Ide F, et al. "Subpontic cartilagenous hyperplasia of the mandible". Oral Diseases 9 (2003): 224-225.

12. Islam MN., et al. "Three cases of subpontic osseous hyperplasia of the mandible: a report". Quintessence International 41 (2010): 299-302.

13. Kato S., et al. "Subpontic tissue enlargement of the mandible following cross-arch fixed partial denture reconstruction: an 18-year follow-up". The International Journal of Prosthodontics 23 (2010): 243-245.

14. Kessler HP and Phillips D. "Oral and maxillofacial pathology case of the month. Bilateral supbontic osseous hyperplasia". Texas Dental Journal 123.1153 (2006): 1156-1159.

15. Lee CA., et al. "Subpontic osseous hyperplasia: a case series and literature review". General Dentistry 62.4 (2014): 46-52.

16. Lorenzana ER and Hallmon WW. "Subpontic osseous hyperplasia: a case report". Quintessence International 31 (2000): 57-61.

17. Mcdowell JA and Regli CP. "A Quantitative Analysis of the Decrease in Width of the Mandibular Arch during Forced Movements of the Mandible". Journal of Dental Research 40 (1961): 1183-1185.

18. Mesaros AJJR and Evans DB. "Subpontic osseous hyperplasia". General Dentistry 42 (1994): 264-266.

19. Morton TH and JR Natkin E. "Hyperostosis and fixed partial denture pontics: report of 16 patients and review of literature". Journal of Prosthetic Dentistry 64 (1990): 539-547.

20. Nakai H., et al. "Osseous proliferation of the mandible after placement of endosseous implants". The International Journal of Oral and Maxillofacial Implants 15 (2000): 419-424.
21. Ralph JP and Caputo AA. "Analysis of stress patterns in the human mandible". Journal of Dental Research: SAGE Journals 54 (1975): 814-821.

22. Regli CP and Kelly EK. "The phenomenon of decreased mandibular arch width in opening movements". Journal of Prosthetic Dentistry 17 (1967): 49-53.

23. Render PJ. "Bony deposition under a fixed partial denture". Journal of Prosthetic Dentistry 54 (1985): 524-525.

24. Ruffin SA., et al. "Diagnosis and treatment of subpontic osseous hyperplasia. Report of a case". Oral Surgery, Oral Medicine, Oral Pathology, and Oral Radiology 76 (1993): 68-72.

25. Savage NW and Young WG. "Reactive subpontine exostoses". Oral Surgery, Oral Medicine, Oral Pathology, and Oral Radiology 63 (1987): 498-499.

26. Strassler HE. "Bilateral plateauitization". Oral Surgery, Oral Medicine, Oral Pathology, and Oral Radiology 52 (1981): 222.

27. Takeda Y., et al. "Bilateral subpontic osseous hyperplasia. A case report". Journal of Periodontology 59 (1981): 311-314.

28. Taylor TD. "Osteogenesis of the mandible associated with implant reconstruction: a patient report". The International Journal of Oral and Maxillofacial Implants 4 (1989): 227-231.

\section{Assets from publication with us}

- Prompt Acknowledgement after receiving the article

- Thorough Double blinded peer review

- Rapid Publication

- Issue of Publication Certificate

- High visibility of your Published work

Website: www.actascientific.com/

Submit Article: www.actascientific.com/submission.php

Email us: editor@actascientific.com

Contact us: +919182824667 